\title{
Familia, envejecimiento y discapacidad en España ${ }^{1}$
}

\author{
Ainhoa Alustiza Galarza* \\ Julio Pérez Díaz** \\ *Universitat Autònoma de Barcelona. Centre d'Estudis Demogràfics \\ aalustiza@gmail.com \\ **Instituto de Economía, Geografía y Demografía, CSIC \\ julio.perez@cchs.csic.es
}

Recibido: 25-09-2007

Aceptado: 05-05-2008

\section{Resumen}

Durante el año 2003, en aquel momento como Centro de Estudios Demográficos, se nos encargó el informe general de la Encuesta sobre discapacidades, deficiencias y estado de salud, 1999. Dicho informe, elaborado con la experta colaboración del Grupo de Investigación sobre Envejecimiento (CSIC), se publicó en 2005. Aunque la discapacidad es lógicamente su objetivo principal, la fuente está claramente diseñada para sondear la relación existente entre quienes padecen estos problemas y su entorno familiar inmediato. Esta virtualidad es la que se ha pretendido explotar temáticamente aquí. En el presente artículo, se exponen algunos de los resultados obtenidos en el informe, articulados temáticamente en torno a estos dos terrenos, el de la edad y el del entorno convivencial inmediato.

Palabras clave: familia, edad, envejecimiento, salud, discapacidad, España.

\section{Abstract. Family, ageing and disability in Spain}

During the year 2003, the Demographic Studies Center was in charge of the general report of the Survey about Discapacities, Deficiencies and the State of Health, 1999. This report, elaborated with the expert collaboration of the Research Group on Ageing (CSIC), was published in 2005. Although disability logically is its primary target, the source is clearly designed to sound out the existing relation between those who suffer these problems and their immediate family environment. This potential has been tried to exploit thematically here. In the present article some of the results obtained in the report are exposed, thematically formulated around these two areas: age and the immediate co-habitational environment.

Key words: family, age, aging, health, disability, Spain.

1. Este artículo, ha sido posible gracias al encargo del INE y el IMSERSO de realizar un informe general de la Encuesta sobre Discapacidades, Deficiencias y Estado de Salud, 1999. Emplea también mucha de la información utilizada por los mismos autores en «Los mayores en la Encuesta sobre Discapacidades, Deficiencias y Estado de Salud, 1999", artículo publicado en Perfiles y tendencias. Boletin sobre el envejecimiento, 14, publicación que también debemos agradecer al Observatorio de las Personas Mayores del IMSERSO.

El artículo se enmarca en las actividades de Julio Pérez Díaz como miembro del grupo consolidado de investigación Grupo de Estudios Demográficos y de Migraciones (GEDEM) con la identificación 2005SGR00930 (Generalitat de Catalunya). 


\section{Sumario}

\author{
Introducción y algo de historia sobre \\ la fuente \\ El volumen y la distribución por edad \\ y sexo de los afectados \\ El inicio de la discapacidad \\ Tipología y causas de la discapacidad
}

El entorno familiar

Ayuda personal y papel de la familia

Últimos apuntes y consideraciones

Bibliografía

\section{Introducción y algo de historia sobre la fuente}

La ancestral dinámica poblacional del ser humano y los equilibrios tradicionales entre nacimientos y defunciones vienen experimentando un cambio radical en los últimos dos siglos. En términos históricos, es muy poco tiempo, pero para los políticos y planificadores que se las han de ver con los cambios vertiginosos que el proceso ha desencadenado, los tiempos de reacción son mucho menores. En particular, los responsables del sector sanitario ven frecuentemente con alarma el rápido envejecimiento demográfico, con lo cual pierden la perspectiva amplia que evidencia el gran éxito experimentado por la vida humana.

Todo empieza con el descenso de la mortalidad en algunas partes de la Europa del siglo XVIII. Ello pone en marcha una oleada que, con más o menos desfase, ha llegado a todo el planeta. El sistema demográfico y reproductivo anterior, durante miles de años, padecía una extremada precariedad y nunca permitió esperanzas de vida superiores a los treinta y cinco años. De hecho, al menos la mitad de los nacimientos de cualquier generación había fallecido antes de que alcanzase siquiera la pubertad.

La esperanza de vida de los actuales países desarrollados ronda e incluso supera los ochenta años, pero incluso los países en desarrollo, salvo muy contadas excepciones, muestran una tendencia sostenida y clara en la misma dirección.

Los efectos de un cambio de tal magnitud no sólo son considerables en nuestra estructura social y en la significación de las distintas edades, sino que afectan incluso a nuestros propios cuerpos y a su relación con el entorno. La vida media y el estado físico colectivo han mejorado notablemente y, precisamente por ello, la discapacidad puede reclamar hoy mucha más atención que antaño. Sin embargo, las bases para su estudio son sólo incipientes.

El análisis de la mortalidad cuenta en España con fuentes estadísticas y registros de una antigüedad, constancia y calidad suficientes desde hace más de un siglo. En cambio, la salud colectiva y, particularmente, el efecto de sus deficiencias sobre la vida cotidiana apenas cuentan con fuentes estadísticas de carácter universal. Ha hecho falta esperar al pleno desarrollo de los modernos sistemas sanitarios nacionales para que la salud de la población en su conjunto pueda ser vista como un objeto de interés que justifique operaciones estadísticas específicas de gran envergadura. 
La discapacidad ha debido esperar aún más para adquirir relevancia en la opinión pública ${ }^{2}$. En sí misma, no es un problema de la salud, sino el impacto que tales problemas tienen sobre la vida cotidiana. El carácter reciente de las fuentes estadísticas españolas sobre este tema ${ }^{3}$ es compartido por el conjunto de los países más desarrollados. En todos ellos, los motivos son similares y múltiples, expresiones del nuevo contexto socioeconómico del mundo desarrollado, "postindustrial», que se dibuja ya con claridad en los años ochenta:

- En términos muy generales, se ha trasladado el énfasis desde la cantidad hacia la calidad de los años de vida. En el ámbito de la salud, esta traslación se traduce en una creciente preocupación por la integración social y la adecuación del ciclo vital en su conjunto, y no sólo por el tratamiento de los problemas funcionales. Para ser operativa, esta nueva orientación requiere necesariamente información estadística amplia sobre los efectos e interrelaciones entre la salud y la vida cotidiana.

- El aumento de la siniestralidad de tráfico y sus secuelas. Problema muy concreto, compartido con escasas diferencias temporales por la mayor parte de los países más desarrollados. Mientras se avanza en darle respuesta, y aunque los afectados constituyan una parte pequeña de la población, su incidencia en las edades jóvenes es importante y las discapacidades a que da lugar son de una gravedad considerable.

- El envejecimiento demográfico ha alcanzado umbrales significativos, como aquel en que los mayores rebasan la proporción de menores de quince años (en España, se cruza dicho umbral a finales de los años noventa). La supervivencia de los mayores, además, sigue mejorando sostenidamente (contra todos los pronósticos, que preveían un agotamiento de las mejoras allá por la década de los ochenta). El efecto «mecánico» es un incremento sustancial de quienes padecen discapacidades y de quienes demandan cuidados de larga duración, al margen de posibles mejoras en la prevalencia de tales problemas.

- Finalmente, la propia demanda social es creciente, no sólo desde el punto de vista cuantitativo. El grado de exigencia de calidad de vida ha aumentado notablemente, y la evolución tecnológico-ergonómica del entorno hace cada vez más dramático el contraste entre las situaciones de deficiencias resueltas o sin resolver. En este sentido, asistimos a un notable impulso institucional cuya más reciente expresión es la Declaración de Madrid, resultante del Congreso Europeo de las Personas con Discapacidad (marzo de 2002), así como el Año Europeo de las Personas con Discapacidad (2003).

En este nuevo contexto socioeconómico, el Instituto Nacional de Estadística (INE), en colaboración con el IMSERSO, llevó a cabo, durante el año 1986,

2. Encuesta de Bienestar Social de la ONCE, 1996-1997.

3. Durán (2002) dedica un completo anexo a enumerar y comentar de forma exhaustiva las fuentes existentes. Puede así comprobarse que las más importantes son prácticamente de la década de los noventa. 
la Encuesta sobre Discapacidades, Deficiencias y Minusvalías, primera fuente de envergadura sobre la interrelación entre los problemas de salud y las funciones a las cuales afectan. Se acomodaba a los criterios de la OMS y permitía directamente, por primera vez en España, el cálculo de la esperanza de vida en salud, indicador sintético que empezaba a tener cierto predicamento y hacía posible la comparación internacional y la construcción de series históricas en futuras ediciones (véase INE, 2005).

Desde entonces, el panorama ha seguido cambiando. La esperanza de vida no ha tocado techo después de que las mejoras de la mortalidad infantil, ya muy escasas, dejaron de ser la principal fuente de años adicionales con que mejorar el indicador. Por el contrario, ha seguido su curso ascendente, de forma pasmosamente sostenida, gracias a las imprevistas mejoras de la mortalidad a edades avanzadas.

Por otra parte, ha podido comprobarse que ese «plus» imprevisto no va acompañado de la pandemia de enfermedades y discapacidades que cabía esperar de la consecuente proliferación de personas mayores. En la última década del siglo XX, la OMS ha puesto a punto nuevas herramientas de medición de la esperanza de vida en salud que han proporcionado, por primera vez, un panorama internacional completo. Nos dicen que son los países con mayor esperanza de vida los que tienen, además, una menor proporción de la vida afectada por la mala salud, e incluso un menor número absoluto de años de vida aquejados por tales problemas.

En este nuevo contexto, donde los intereses y los problemas han cambiado sustancialmente, se elabora la Encuesta de Deficiencias, Discapacidades y Estado de Salud (EDDES en adelante), una gran operación estadística que les dé respuesta.

La EDDES de 1999 es una macroencuesta realizada nada menos que sobre 79.000 viviendas y a 220.000 personas, fiel reflejo del actual interés por el tema (en esta ocasión, junto al INE y el IMSERSO, se cuenta con la financiación de la Fundación ONCE). Aunque pretende seguir la línea de la encuesta anterior, presenta novedades sustanciales. En general, sus criterios son más exigentes a la hora de identificar discapacidades, ha abandonado prácticamente el concepto de minusvalía (central en la encuesta de 1986) y ha puesto mayor énfasis en el grado de severidad y el entorno familiar e institucional. Adopta los últimos criterios de la OMS en la clasificación de las discapacidades e incluye un cuestionario particular para investigar el estado de salud del conjunto de la población.

Todo ello hace que la actualización conceptual y temática se haya conseguido sacrificando la comparabilidad con la encuesta anterior. Como ha ocurrido en tantas otras ocasiones, hasta que las fuentes estadísticas se consolidan y se convierten en operaciones periódicas, disponemos de una extraordinaria fuente por su detalle y representatividad, pero apenas podemos usarla para estudiar el cambio histórico experimentado por su objeto de estudio, la discapacidad. En cambio, y puesto que una de las prioridades en su diseño fue discernir en las relaciones, estructuras e influencias sobre todos los miembros de 
Gráfico 1. Pirámide de la población de seis y más años con o sin discapacidad
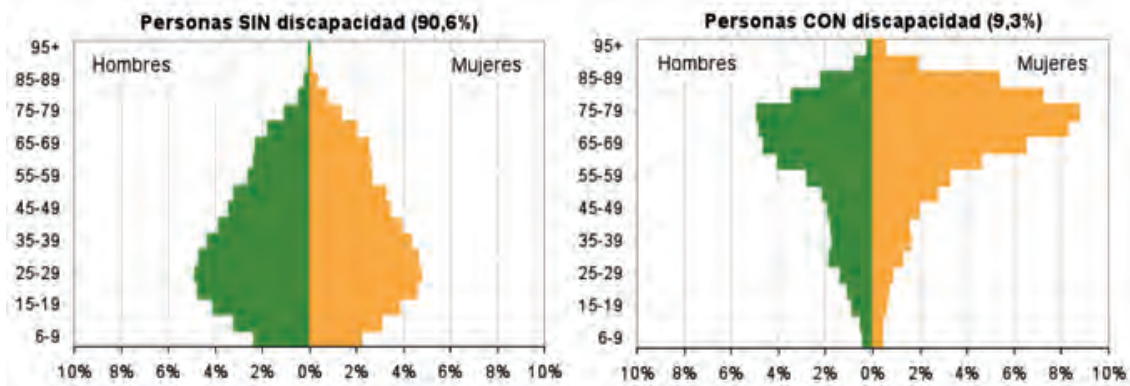

Fuente: elaboración propia a partir de la EDDES de 1999.

los hogares en los que alguna persona padece discapacidad, sí es una excelente ocasión para describir y analizar la situación familiar y convivencial en tales hogares. Esta óptica descriptiva es la que se va a emplear aquí para hacer un breve cuadro de la relación entre la discapacidad, la edad (especialmente la edad avanzada) y la convivencia en el propio hogar.

\section{El volumen y la distribución por edad y sexo de los afectados}

Éste es un elemento conceptual básico para enlazar temáticamente los cambios demográficos con los de la salud colectiva. La estrecha relación entre sexo, años de vida y aparición de ciertos efectos discapacitantes en los problemas de salud se combina con el envejecimiento demográfico para construir un primer entramado explicativo de la actual dimensión poblacional de la discapacidad.

Según los datos obtenidos de la EDDES, la población que declaraba tener algún tipo de discapacidad ascendía a 3.528.222 personas, alrededor del $9 \%$ de la población total ${ }^{4}$. Pero el predominio de los mayores y el mayor componente femenino son harto evidentes.

Es bien conocida la correlación entre edad y discapacidad; es en la vejez cuando tales problemas alcanzan proporciones notables. Así, a los 65-69 años, 190 de cada 1.000 personas están afectadas, a los 80-84 años representan un 475\% y se alcanza el $841 \%$ entre los de más de 95 años. Se entiende, así, que la edad media de quienes padecen discapacidades sea de 62,7 años, mientras que la del resto de la población es de 36,4.

Otro punto conocido es que existen diferencias sustanciales en el número de afectados de cada sexo: 2.055.250 mujeres frente a 1.472.972 hombres (un $65 \%$ y un $35 \%$ respectivamente). Pero esta característica está más relaciona-

4. Estos datos incluyen las personas de 0-5 años que padecen alguna limitación. 
Gráfico 2. Evolución de la discapacidad por edad y sexos (tasa por 1.000 habitantes de cada grupo de edad y sexo)

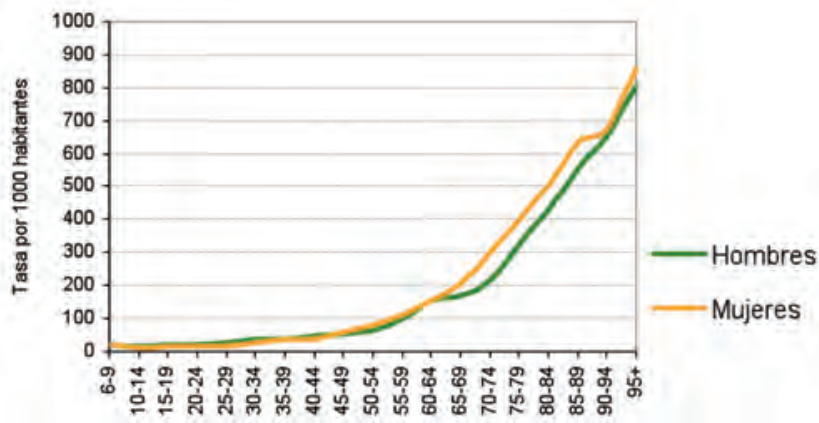

Fuente: elaboración propia a partir de la EDDES de 1999.

da con la menor supervivencia de los hombres que con su mejor salud. La prevalencia de la discapacidad es ligeramente superior entre las mujeres sólo a partir de la primera vejez (gráfico 2), mientras que, en los menores de 40 años, los hombres que padecen discapacidades son sustancialmente más numerosos que las mujeres en la misma situación (gráfico 3).

Muchas de las discapacidades de los jóvenes en estas edades están relacionadas con problemas de movilidad, que, en la mayoría de los casos, se originan en causas «externas» evitables, generalmente asociadas con accidentes de trabajo y de tráfico. Por otra parte, entre los más pequeños, existe también entre los varones una mayor incidencia, aunque ligera, de la mortalidad y las deficiencias por causas de origen genético o relacionadas con la gestación.

Gráfico 3. Índice de masculinidad (IM) por grupos de edad

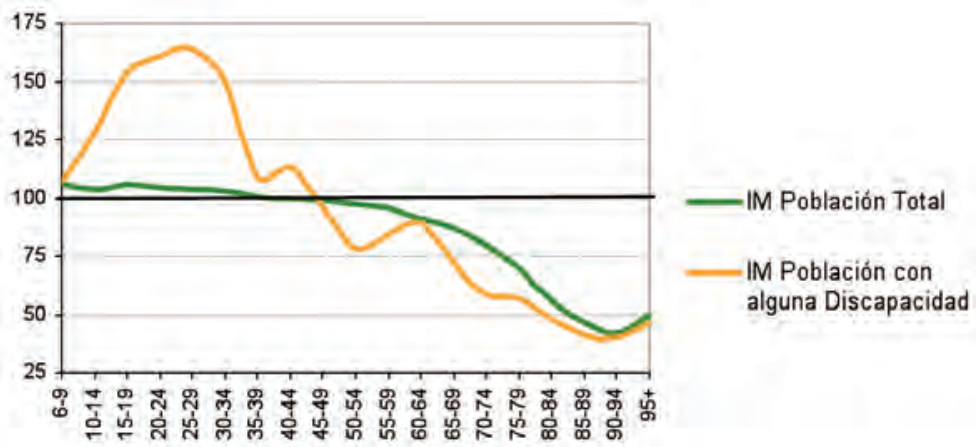

Fuente: elaboración propia a partir de la EDDES de 1999.

Nota: el «índice» o «relación de masculinidad» se obtiene simplemente dividiendo en cada edad el número de hombres por el de mujeres y convirtiéndolo en un porcentaje. Así expresado, indica el número de hombres por cada cien mujeres. 
Gráfico 4. Probabilidad de empezar a padecer alguna discapacidad, por sexo y edad (probabilidad simple y probabilidad acumulada)
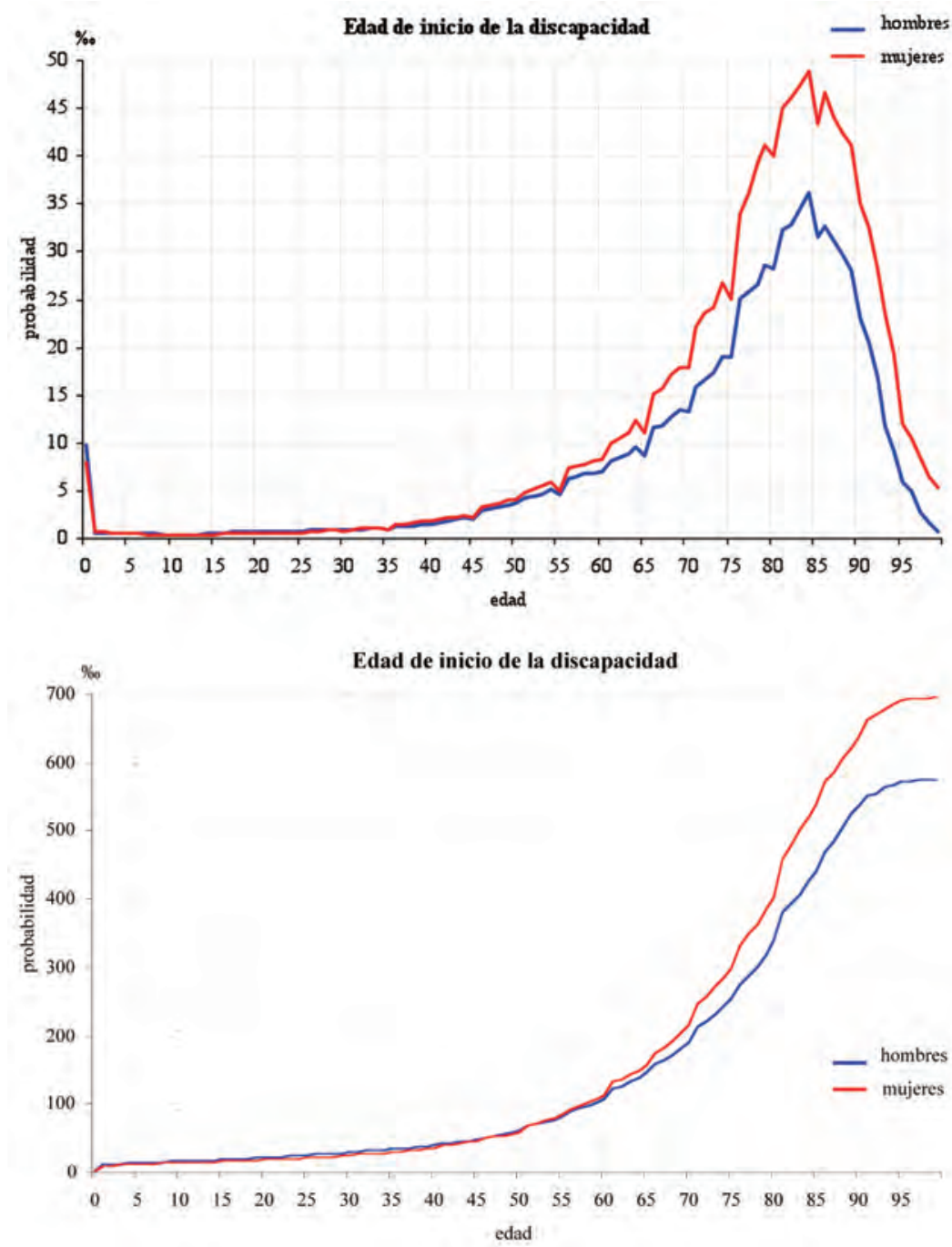

Fuente: elaboración Instituto de Economía y Geografía del CSIC con datos de la EDDES de 1999, para el informe general de la EDDES de 1999.

Podría pensarse, por tanto, que la «sobreabundancia» de mujeres mayores con discapacidad es sólo el resultado de la «sobremortalidad» masculina. Sin embargo, no sólo el número, sino también la proporción, es ligeramente superior en las mujeres de estas edades. Esta persistencia del fenómeno, en cierto modo contra- 
dictoria con la mayor supervivencia femenina, no tiene que ver únicamente con la salud. Entre salud y discapacidad existen, como mediadores diferenciales según el sexo, ciertos factores socioeconómicos, tales como los menores ingresos económicos femeninos o una mayor frecuencia de la viudedad y la soledad.

Es posible que también la relación diferente con el ámbito laboral y el del hogar haya marcado a los más mayores. Los hombres habrían tenido una relación con el mundo médico muy limitada a las bajas laborales por enfermedad, mientras que las mujeres han hecho un uso de tipología más extensa, no sólo personal sino también ligado al cuidado de otros familiares. El hecho es que el número de discapacidades originadas en deficiencias médicamente diagnosticadas era tres veces superior en el caso de las mujeres que entre los hombres, cosa que difícilmente puede explicarse por diferencias fisiológicas entre unos y otros.

\section{El inicio de la discapacidad}

La edad a la que se padece por primera vez una discapacidad no es suficiente como indicador resumido de la situación en los distintos momentos del ciclo vital (falta saber si hubo recuperación, si, por el contrario, se añadieron otras discapacidades posteriormente, cual es su grado de severidad, etc.), pero permite conocer la distinta incidencia del «riesgo» en las edades. Para calcular estas probabilidades, se contabilizan las apariciones de nuevos casos de discapacidad sobre población aún no discapacitada.

El primer gráfico muestra la probabilidad de inicio de la discapacidad en cada edad. Es progresivamente creciente con la edad, y la progresión se acelera especialmente entre quienes rebasan los 60 o 65 años. La probabilidad máxima de que alguien que no padecía discapacidades previamente empiece a tenerlas se produce entre los 80 y los 90 años, y a partir de esta edad se ralentiza.

La probabilidad acumulada de caer en discapacidad (segundo gráfico) es muy parecida a la tasa de discapacidad que se ha presentado en el gráfico 2. Las curvas muestran cómo el haber padecido la primera discapacidad se hace más frecuente con la edad, especialmente a partir de los 65 años (a los 50 años, los afectados son solo el 9\%, pero a los 65 años ya alcanzan el 23\%), aunque también es perceptible la ralentización con que aumentan los afectados a partir de los 90 años $^{5}$.

5. Por un lado, hay personas que mueren sin haber padecido ningún tipo de discapacidad y, por otro, a partir de los 90 años es más frecuente el inicio de una segunda discapacidad que no el de una primera. Abellán y Puga, en el informe general de la EDDES (INE, 2005: 41-42) afirman: «Esta caída del ritmo de entrada puede deberse a un tamaño muestral reducido, debido a una salida de observación de muchos individuos de las cohortes consideradas, por mortalidad, o por abultada entrada previa en dicha discapacidad, durante las edades de máximo riesgo, produciéndose de esta forma un efecto de selección de la población que alcanza edades avanzadas sin discapacidad. A este efecto se suma la posibilidad de que algunos ancianos, quizá los que estén en peores condiciones de fragilidad, hayan pasado a alojamientos colectivos (residencias), que no han sido incluidos en la EDDES; también a que no responden con la misma disposición las personas más mayores, de 90 y más años, pues tienen más asumido que es una situación normal, una fragilidad adquirida, lo que con 60 años sería una discapacidad clara». 


\section{Tipología y causas de la discapacidad}

Teniendo en cuenta lo dicho hasta ahora, no es de extrañar que las discapacidades más frecuentes sean las que van surgiendo progresivamente con la edad. En efecto, son las relacionadas con la movilidad (sobre todo los desplazamientos fuera del hogar y también los desplazamientos o movimientos del propio cuerpo), y éstas a su vez son precisamente las más características de los mayores. Existen más de dos millones de personas, el 60\% de todas las que declaran padecer alguna discapacidad, que presentan dificultades para desplazarse fuera del hogar, básicamente para poder utilizar algún medio de transporte público y para desplazarse por su propio pie. Alrededor de dos tercios de ellos son personas de edad y la proporción es sumamente elevada en los grupos de los más mayores. Así, el 35\% de los que superan los 80 años presenta dificultades para andar y el 38\%, para viajar en transporte público. Dentro del propio hogar, más de un millón de personas tienen problemas para levantarse, acostarse y, especialmente importante, permanecer de pie, situación que generalmente implica gravedad y que afecta a personas muy mayores.

Todas estas discapacidades relacionadas con la movilidad hacen que la vida de los que las padecen se vea limitada en numerosos sentidos. El espacio físico al que pueden acceder se reduce, esto hace que no tengan pleno acceso al ámbito en el que se desarrolla la vida comunitaria y, por lo tanto, a las ventajas que se obtienen de vivir en la sociedad.

También son muy numerosas aquellas discapacidades que impiden o dificultan el cuidado de uno mismo, sobre todo las tareas ligadas al aseo personal, vestirse y desvestirse, el control de las necesidades y la utilización del aseo. En términos absolutos, la población total que presenta problemas para cuidar de sí misma no es la más numerosa. Sin embargo, entre la población mayor, sobre todo entre los octogenarios, sí son muy abundantes este tipo de problemas, padecidos además con mayor gravedad en cuanto a la dependencia de ayuda personal que generan.

Todas las discapacidades tienen como origen deficiencias de la salud, pero no siempre es fácil o posible establecer la relación exacta, ya sea por la posible multiplicidad de las deficiencias causantes o porque el mismo entrevistado encuentre difícil hacer tal identificación.

En cualquier caso, también encontramos que las deficiencias más frecuentes están muy relacionadas con las personas mayores. Las más comunes son deficiencias sensoriales, si se suman las que afectan a la visión y a la audición (cada una de estas deficiencias abarca alrededor del 16\% de todas las deficiencias). Este tipo de deficiencias son sólo algo más frecuentes entre las que afectan a los más mayores, pero el siguiente tipo en importancia, las deficiencias que afectan al sistema osteoarticular, supone el 30\% del total de las deficiencias y su relación con la edad es mucho más directa. Se trata de privaciones o alteraciones mecánicas y motrices, que tienen su origen en lesiones de los elementos de sostén del cuerpo. Su prevalencia es superior entre la población 
femenina. De 1.467.921 personas que padecen alguna discapacidad osteoarticular, dos tercios son mujeres, la mayoría de ellas de más de 65 años.

Otras de las deficiencias más frecuentes son las llamadas «deficiencias múltiples» y las relacionadas con los trastornos mentales. Las deficiencias múltiples afectan a varios órganos, ya sea por causas congénitas o adquiridas. En el caso de las congénitas, el efecto no debe ser importante en las edades mayores, y es posible que haya incluso menores probabilidades de llegar a esas edades entre quienes las padecen. Pero las adquiridas obedecen a procesos degenerativos en los que la edad de la persona es el factor decisivo. Es por ello que el $95 \%$ del total de tales deficiencias corresponde a mayores de 65 años, y casi el $60 \%$ se presenta en personas de más de 80 años.

Entre las deficiencias mentales, destacan las demencias y los denominados "otros trastornos mentales», que incluyen trastornos mentales orgánicos, autismos, esquizofrenias, fobias, obsesiones, trastornos somáticos, hipocondrías, trastornos psicóticos, del ánimo, de ansiedad, de personalidad, etc. Este segundo grupo se reparte de forma parecida entre la población de 20 a 79 años, y se trata de una de las deficiencias más frecuentes en el grupo de personas de 20 a 44 años. Pero el primer tipo de deficiencias mentales, las demencias, es casi exclusivo de las personas de 65 y más años (el 95\% corresponde a personas que superan dicha edad y el $57 \%$ a mayores de 80 años).

La causa más frecuente de las deficiencias, más del $60 \%$ de los casos, es la enfermedad común. Su presencia se agudiza entre los más mayores, cuyas proporciones son más elevadas que en el resto de la población. Además, las tres cuartas partes de las deficiencias causadas por enfermedades comunes se concentran en la población de 65 y más años.

La segunda causa más común, aunque muy por debajo de la anterior, es la categoría etiquetada en la EDDES como «otras causas». La inclusión bajo este epígrafe de aquellos procesos degenerativos derivados de la edad como origen de deficiencias (múltiples, sobre todo), ha hecho posible relacionar los efectos del envejecimiento demográfico en el estado de salud de la población y de la población mayor en particular. Este problema se concentra (en más del 76\% de los casos) entre la población de 65 y más años y es especialmente importante entre los octogenarios (en el $28 \%$ de los casos es el origen de las deficiencias que padece dicha población).

El resto de los problemas son responsables de menos del 7\% de los casos, y en ellos cabe incluir los accidentes laborales y de tráfico, que afectan sobre todo a jóvenes y adultos. Pero en este grupo están también los accidentes domésticos, que se concentran, en términos absolutos, sobre todo en las personas de más edad: alrededor del $70 \%$ de las personas con deficiencias víctimas de dichos accidentes superan los 65 años y son especialmente frecuentes entre los octogenarios.

\section{El entorno familiar}

Las residencias colectivas y el entorno institucional han sido lugares privilegiados para la concentración de personas con discapacidades graves y escasa 
ayuda informal, pero no son un buen observatorio para dibujar una panorámica general de la relación con la discapacidad del conjunto de la población. Por eso, y puesto que se sabe bien que el apoyo informal es abrumadoramente superior al institucional, tales establecimientos quedan excluidos del universo de la EDDES de 1999, que sólo pasó sus cuestionarios en los hogares. Es ahí precisamente donde hasta ahora se ha generado menos información en este asunto, situación que la encuesta pretende paliar.

Añádase que el propio concepto de «discapacidad» se refiere a las actividades comunes que las deficiencias de la salud impiden o dificultan, de modo que es en el entorno informal, cotidiano, donde tiene pleno sentido estudiarla. Por tanto, el diseño completo de la encuesta, además de los temas relativos a la salud y sus deficiencias, pone un especial énfasis en captar información sobre el contexto social y familiar.

En este tema, conviene tener presente que, por mucho que hayan mejorado y crecido históricamente los recursos materiales y sociales disponibles o haya mejorado la adaptación del entorno a nuestras necesidades, la autonomía absoluta sigue siendo igualmente quimérica. La necesidad de mediaciones humanas y materiales no es un resultado de la discapacidad; simplemente se acentúa con ésta. El hogar es donde dichas necesidades alcanzan su mayor cobertura, se sufran o no discapacidades, y por ello resulta especialmente interesante analizar la estructura y la tipología de los hogares en los que conviven los afectados y no afectados por alguna discapacidad, así como la provisión de cuidados y la ayuda en los casos en los que sea necesario. Obviamente, al margen de consideraciones sociales o culturales, la etapa del ciclo vital es un fuerte condicionante en este tema, de modo que la relación entre vejez y discapacidad tiene una traducción casi directa en términos de convivencia y tipología de los hogares.

\section{El tamaño de los hogares}

Según la EDDES, el número medio de residentes en los hogares españoles es de 3,06 personas. Se trata de un mínimo histórico, inferior casi exactamente en una persona respecto a los datos del censo de población de $1960^{6}$.

Aunque esta disminución progresiva en el tamaño de los grupos convivenciales sea la norma "modernizadora» universal, y pese a que suele atribuirse sólo a los cambios en las pautas nupciales y reproductivas, resulta también en muy buena parte del mero envejecimiento demográfico; los mayores, cada vez más representados en el conjunto de la población, están en aquella fase del ciclo vital en que los hijos ya se han emancipado (la fase de "nido vacío») y muchos de ellos (especialmente de ellas) han llegado también a aquella situación, inexorable, en que la pareja fallece.

6. A pesar de dicho descenso, España sigue siendo el país de la UE con un mayor tamaño medio de los hogares, que, en el conjunto de la Unión, no llega a las 2,5 personas. 
Atendiendo a la «principalidad» de las personas que integran el hogar, la encuesta confirma las conocidas diferencias entre sexos en lo que se refiere al tamaño de los hogares: los encabezados por hombres, además de resultar más abundantes $(79 \%)$, tienen un mayor tamaño medio (3,32 personas frente a 2,08 , cuando la persona principal es mujer). Son diferencias que se explican por la combinación de dos factores: por un lado, las diferencias de género, especialmente importantes en ciertas generaciones, que otorgan al hombre la prioridad como cabeza de familia; pero también interviene la mayor viudedad femenina, resultante de la menor longevidad de los hombres y de la tradicional diferencia de edad entre hombres y mujeres en el momento de casarse.

Los hogares que incluyen alguna persona discapacitada constituyen nada menos que el $23 \%$ del conjunto total. En ellos, la persona principal generalmente sigue siendo un hombre, aunque, en estos casos, la principalidad de las mujeres es bastante más frecuente (en el 30\% de los casos). No obstante, éste tampoco es un resultado atribuible a la discapacidad, sino a su concentración en las edades avanzadas y a la feminización de tales edades. También aquí la tradicional diferencia de edad en el matrimonio aumenta la probabilidad de viudedad entre las mujeres mayores y, por lo tanto, de que sean la persona principal de sus hogares.

\section{La convivencia en las distintas edades}

De forma harto estable y tradicional, las etapas de la vida en que se comparte residencia con más personas son los años de infancia y juventud y los de madurez. El motivo es que son las edades en que el hogar está compuesto más probablemente por, al menos, una pareja y sus hijos (en el primer caso, el sujeto está en la posición de "hijo" y en el segundo, de "progenitor»). Por el mismo motivo, los menores tamaños de convivencia se viven en la etapa de emancipación del hogar de origen, alrededor de los 30 años de edad, y en la etapa en que, habiendo ya constituido un hogar propio, los hijos se han emancipado y la probabilidad de fallecimiento del cónyuge empieza a ser alta. Sin embargo, esta última pauta sólo se cumple hasta cierto umbral. Los que tienen más de ochenta años ven incrementada la compañía en el hogar, y no parece que el padecimiento o no de discapacidades suponga en ello grandes diferencias, a no ser que se introduzca como criterio un grado de severidad suficientemente alto (tres o cuatro discapacidades severas).

Si lo observado es la interacción entre el padecimiento de discapacidades y el tamaño de los hogares en las distintas edades, debe concluirse que la discapacidad a menudo supone trabas para los ciclos vitales y familiares. Los problemas añadidos que puede crear para la emancipación y la vida independiente se traducen en convivencias más reducidas, ya que suponen igualmente una mayor dificultad a la hora de constituir una familia propia. Los niños con limitaciones sí presentan un mayor número de convivientes en su hogar (probablemente reflejo de estrategias familiares de apoyo), pero, en los adultos, la discapacidad tiene el efecto contrario: se emancipan en menor medida y el 
Gráfico 5. Número medio de convivientes según la edad y la existencia de algún miembro con discapacidad

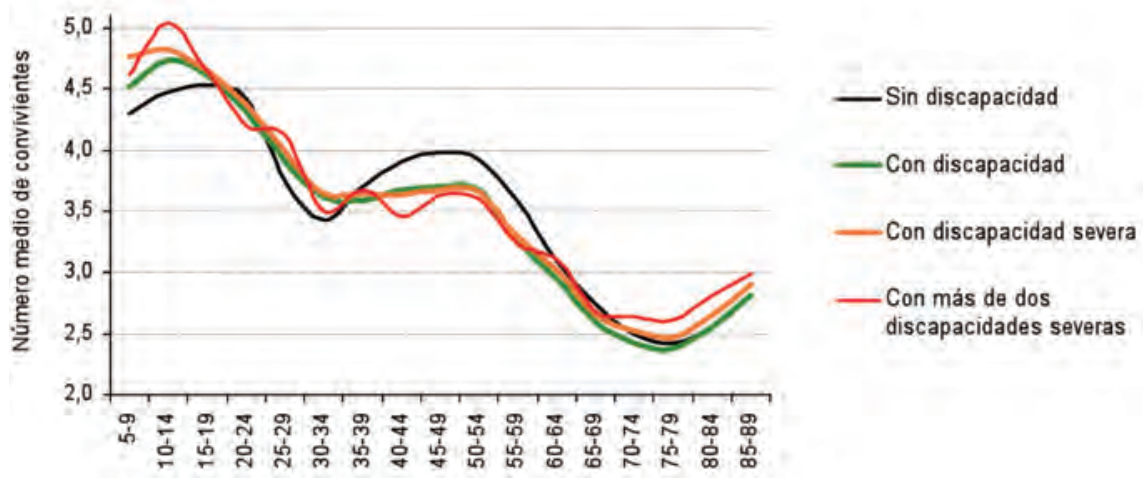

Fuente: elaboración propia a partir de la EDDES de 1999.

emparejamiento y la formación de una familia propia son también menos frecuentes.

La distribución según los distintos tamaños de convivencia corrobora que las personas no afectadas por discapacidad alguna residen en hogares de mayor tamaño. El hogar de cuatro personas es el más frecuente; solamente un 3,9\% vive solo, mientras que entre los que sí presentan alguna discapacidad la proporción supera el 14\%. Existen en ello, además, grandes diferencias en función del sexo: las mujeres que padecen discapacidades viven solas en el 19\% de los casos, mientras que, en los hombres afectados, la proporción es solo del 7\%. Por otro lado, el hogar más frecuente entre aquéllos que padecen alguna discapacidad es aquél formado por dos personas (a menudo, la pareja conyugal).

Pero, de nuevo, el envejecimiento demográfico tiene el principal papel explicativo en estos datos. Son las grandes diferencias numéricas entre hombres y mujeres de edad avanzada, unidas a la mayor prevalencia de la discapacidad en tales edades, las que explican la mayor soledad femenina a tales edades. A edades iguales, las diferencias que introduce el padecimiento de discapacidades entre ambos sexos son muy escasas, de unas pocas décimas.

En definitiva, el principal motivo de escasa convivencia es la edad avanzada, por ir acompañada de la fase de nido vacío y la viudedad, pero también hay motivos generacionales que se añaden a las determinaciones de la edad. Existe también entre los mayores actuales una notable independencia, especialmente entre las mujeres, que hubiese sido mucho menos factible hace sólo algunas décadas.

La ironía se produce porque chocan dos realidades distintas: es aproximadamente entre los 60 y los 80 años cuando los tamaños de los hogares son más reducidos, y es en tales edades cuando mayor impacto tienen las discapacida- 
des en la sostenibilidad de tales pautas residenciales. Las discapacidades acumuladas y de gran severidad imposibilitan la vida autónoma y van asociadas a unos hogares de tamaño sensiblemente mayor que en el resto de personas de la misma edad.

En suma, puede decirse que, en el conjunto de la población, la discapacidad es un factor reductor, no ampliador, del número de personas convivientes, pero, por otra parte, los efectos que se derivan de ella no son demasiado grandes en términos estadísticos. Sólo en los casos de discapacidades acumuladas y con elevada severidad se emplean estrategias de convivencia más numerosa por parte de las familias. Pero, sobre todo, en términos causales, el conjunto de personas con alguna discapacidad está sensiblemente menos acompañado que el resto como consecuencia de una muy diferente estructura por edad, en la que presentan un mayor peso las personas mayores.

\section{La estructura de los hogares}

No es únicamente el tamaño de los hogares el que está cambiando sustancialmente. También lo hace su configuración y composición. Cada vez tienen más peso los hogares unipersonales, los constituidos por parejas (sin hijos convivientes) y los monoparentales. Por el contrario, los hogares familiares «típicos», compuestos por parejas con hijos solteros, aunque siguen siendo mayoritarios, tienen una representación cada vez menor (Requena, 2001).

Es frecuente señalar hacia las nuevas pautas de constitución y disolución de la pareja como la principal explicación de estas tendencias. En ellas, quieren verse los signos del proceso de «modernización» de las conductas conyugales y familiares que conducirían a España en la misma dirección recorrida previamente por otros países de Europa, especialmente los nórdicos. Y es cierto que tales pautas experimentan cambios, y que, incluso en el modelo tradicional de emparejamiento y constitución de familia, las edades medias se han retrasado considerablemente, especialmente el nacimiento del primer hijo. Sin embargo, más que los cambios conductuales, la distribución y la tipología de los hogares españoles está viéndose profundamente modificada por motivos estructurales muy similares a los que explican la progresiva reducción de su tamaño medio.

El principal motor del cambio en las estructuras de los hogares españoles es el envejecimiento demográfico, unido a la cada vez mayor independencia domiciliaria de los mayores, tanto durante la fase de «nido vacío» posterior a la emancipación de los hijos, como en la casi ineludible fase posterior de viudedad. Incluso si se mantuvieran los mismos modelos de ciclo familiar de hace algunas décadas, la disminución del peso de los jóvenes en edad nupcial y el aumento de la proporción de mayores serían motivo suficiente para generar una buena parte del profundo cambio que está experimentando el mapa de los distintos tipos de hogar en España.

Por tanto, y una vez más, resulta imprescindible considerar atentamente el factor edad al comparar las estructuras de los hogares de quienes padecen y de 
Gráfico 6. Personas con o sin discapacidad, según el tipo de hogar en el que viven

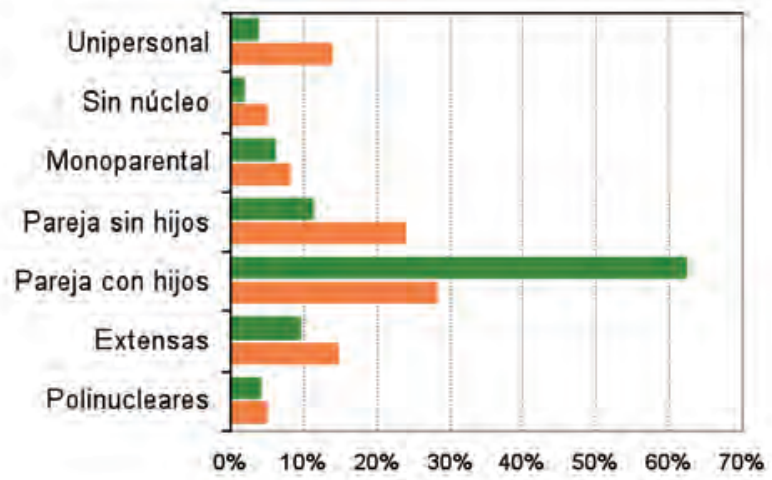

Sin discapacidad

Con discapacidad

Fuente: elaboración propia a partir de la EDDES de 1999.

quienes no padecen discapacidades. Ya se ha adelantado que el 14\% de los primeros vive en un hogar unipersonal, mientras que esa misma proporción para la población no afectada no alcanza el 4\%. Ante la tentación inicial de atribuirlo al abandono por parte de los familiares, un análisis estadístico elemental revela que es, en efecto, el factor edad el que explica principalmente tales diferencias (de hecho, como ya se ha mencionado anteriormente, entre los mayores con discapacidades severas, el número de convivientes es sensiblemente superior al que tienen los mismos mayores en caso de no sufrir discapacidades).

Es a la luz de tales prevenciones como deben observarse los resultados obtenidos de la EDDES sobre la particular tipología convivencial en los hogares de quienes padecen discapacidad.

Ya ha podido comprobarse anteriormente que vivir solo o vivir únicamente con la pareja son las situaciones más frecuentes entre quienes padecen alguna discapacidad. Pero puede comprobarse ahora que, en realidad, todas las formas convivenciales diferentes al hogar nuclear con hijos son más frecuentes entre las personas que padecen alguna discapacidad. En definitiva, y no es casual, es lo mismo que ocurre si se elige a los mayores como foco de atención, independientemente de si están afectados o no por alguna discapacidad. Otra vez, hay que hacer referencia al gran peso de la población mayor entre los que padecen alguna discapacidad. Son personas que ya pasaron en su día por la fase vital en la que el hogar estaba compuesto por la pareja y los hijos. Como puede verse en el gráfico 7 , a partir de las edades maduras, la diversidad en las formas de convivencia crece considerablemente, independientemente de la presencia de discapacidades.

Otra forma de poner en evidencia la prioridad explicativa de los años de vida es el cálculo de la edad media de las personas que conviven en cada tipo 
Gráfico 7. Personas con o sin discapacidad, según laedad y el tipo de hogar
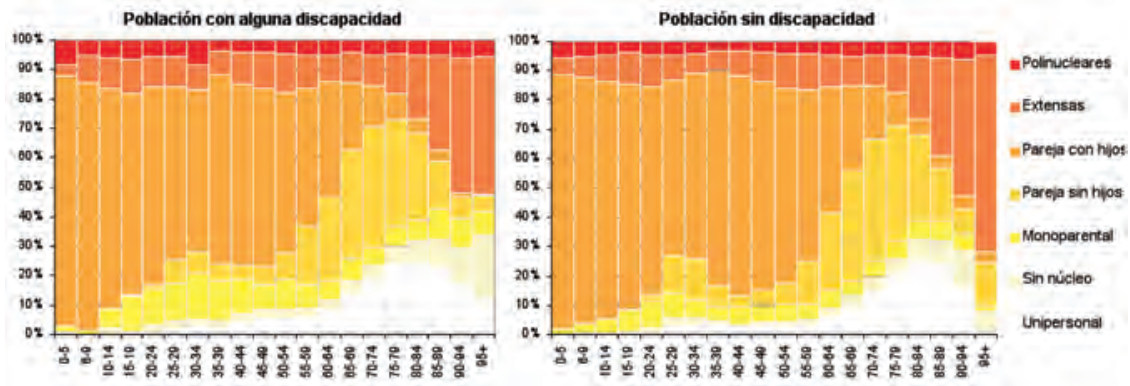

Fuente: elaboración propia a partir de la EDDES de 1999.

de hogar distinguiendo a los afectados por discapacidades. En todos los casos, la edad media de estas personas está muy por encima de la que tienen las personas no afectadas pero con el mismo tipo de hogar, de la misma manera que la edad media de las mujeres supera a la de los hombres siempre que no se convive constituyendo un núcleo conyugal. Así, cuando se trata de hogares unipersonales, muy frecuentes entre aquellos que sí presentan alguna discapacidad, la edad media de las personas no afectadas es de 59,1 años, frente a una edad media de 74,6 años (75,9 en el caso de las mujeres) entre quienes, estando afectados, viven en este tipo de hogares.

Hasta aquí se han considerado características «estructurales» de los hogares, pero la EDDES también permite analizar las características «relacionales», que resultan especialmente importantes en la comprensión de los efectos de la discapacidad.

En las fuentes estadísticas sobre hogares, suele emplearse la identificación de uno de los miembros como persona de referencia en relación a la cual puede definirse el parentesco de las demás. Antaño, era el «cabeza de familia»; más recientemente, se habla de la "persona principal», y en la EDDES se ha optado por que los encuestados señalen a un miembro del hogar como «sustentador principal».

Pese a la discontinuidad de las definiciones y de las fuentes estadísticas, incluso una variable tan simple como ésta, la identidad de la persona de referencia en los hogares, presenta cambios identificables importantes en las últimas décadas en lo que se refiere tanto a la edad como al sexo. Frente a la indudable preponderancia simbólica que tuvo en el pasado el hombre adulto como «sustentador principal», acentuada aún más con la industrialización y la extensión del salario familiar masculino, en las últimas décadas cada vez son más frecuentes los mayores y las mujeres que encabezan hogares.

Resulta tentador ver en ello, de forma exclusiva o principal, un efecto de los cambios conductuales (especialmente entre los jóvenes adultos, que vienen retrasando mucho, durante las últimas décadas, el momento de constituir familia propia). En realidad, una vez más, el principal factor explicativo es el cam- 
bio en la estructura por edades del conjunto de la población. Y es la estrecha relación entre discapacidad y edad la que hace todavía más relevantes las diferencias que, en este terreno, existen entre el conjunto de la población y las personas que padecen discapacidades.

De forma apriorística, podría suponerse que el padecimiento de discapacidades debe reducir las probabilidades de que una persona determinada resulte ser el sustentador principal de su hogar. Sin embargo, los datos hacen reconsiderar la claridad de esta relación.

Según la EDDES, existen 12.835.704 hogares y, por lo tanto, sustentadores principales. De este conjunto total, 2.976.188 son hogares en los que alguno de los miembros padece alguna discapacidad. Pues bien, 1.679.021, más de la mitad, tienen como persona principal a alguien afectado por alguna discapacidad. Se trata de una cantidad muy considerable, nada menos que el 13\% del total de los hogares españoles.

Puesto que ya ha podido comprobarse el elevado número de personas mayores con discapacidades que viven solas, podría sospecharse que estas personas principales con discapacidades son, en realidad, miembros únicos de sus hogares, de modo que su rol no tiene alternativas. Pero si se realiza la desagregación, puede comprobarse que, a pesar de ser el tipo de hogar más habitual, solamente el $29 \%$ de los que son a su vez discapacitados y sustentadores principales viven en un hogar unipersonal, lo cual significa que más de dos tercios de los sustentadores principales con alguna discapacidad conviven con alguien que está siendo «sustentado». También se podría pensar que se trata de personas que conviven con su pareja. Pero, de nuevo, éstos tan solo constituyen el $25 \%$ de todos los casos. Hay que concluir, por tanto, que la discapacidad no es en absoluto incompatible con el mantenimiento del propio hogar, y que, de hecho, es un estado muy habitual entre los más mayores. Con toda seguridad, la pensión o el patrimonio de estas personas debe constituir en muchos casos el principal soporte económico de muchos hogares en los que conviven otros familiares.

En cuanto a las características de las personas con alguna discapacidad que asumen la principalidad de su hogar, cabe decir que están concentradas en las personas más mayores, entre 60 y 89 años y con el máximo de los casos entre los 70 y 79 años, independientemente del tipo de hogar en el que vivan o de su sexo. Además, lo más frecuente es que padezcan algún tipo de discapacidad grave o total, es decir, la actividad básica cotidiana afectada por su discapacidad no les resulta simplemente más difícil, sino que, en muchos casos, simplemente no pueden realizarla. Son porcentajes que van incrementándose conforme aumenta su edad, de manera que llegan a superar a los 95 y más años el $78 \%$ del total de sustentadores.

En función del sexo, existen también diferencias en cuanto al tipo de hogar que se sustenta. Las mujeres con discapacidades que son sustentadoras principales suelen presentar dicho estatus cuando viven solas, cuando son las progenitoras de un hogar monoparental o cuando forman un hogar sin núcleo. Los hombres, en cambio, presentan pocas diferencias en función del padeci- 
Gráfico 8. Personas con discapacidad que, a su vez, son sustentadoras principales de sus hogares, por edad y tipo de hogar en el que viven
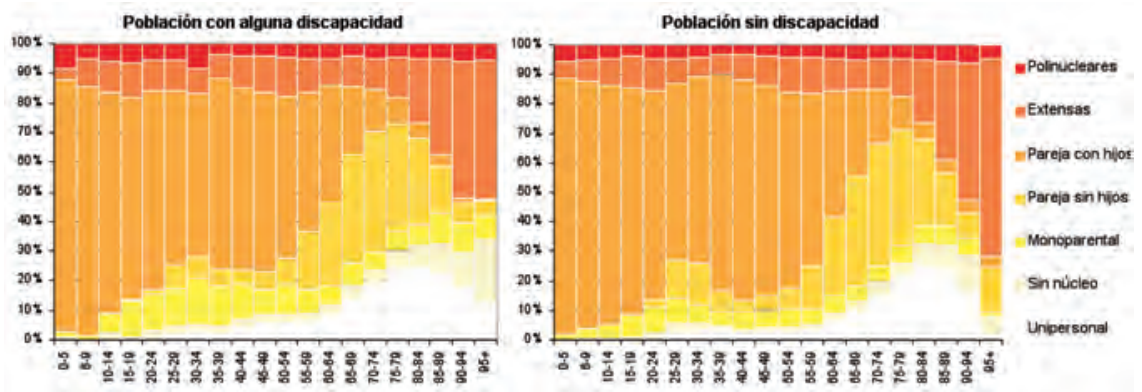

Fuente: elaboración propia a partir de la EDDES de 1999.

miento de discapacidades; son principalmente sustentadores principales en los hogares en los que el núcleo conyugal sigue intacto, es decir, en los hogares nucleares con hijos o sin hijos, los extensos y los polinucleares.

\section{Ayuda personal y papel de la familia}

En las redes familiares, se producen donaciones e intercambios de bienes y de servicios que quedan al margen del mercado y resultan de difícil estudio con las fuentes corrientes. Puesto que la discapacidad implica, casi por definición, la necesidad de ayudas para realizar las actividades que entrañan dificultad, la vertebración entre las pautas de apoyo familiar y las ayudas a los miembros con discapacidades es muy intensa.

La EDDES, con una orientación mucho más social que su único antecedente de 1987, concede en su cuestionario una relevancia especial a tales ayudas. Las preguntas sobre dicho tema pretendían indagar sobre la demanda de cuidados, las discapacidades que requieren más ayudas, las características de los solicitantes, el grado de cobertura de las solicitudes de ayuda y, sobre todo, la identidad de quienes las proporcionan.

Una primera característica es que resultan mucho más frecuentes que las ayudas estrictamente técnicas. De las 3.478 .643 personas con discapacidad, algo menos de la mitad (1.670.450) recibía algún tipo de cuidado personal y un $28,5 \%$ (991.259) recibía alguna ayuda técnica.

La clase de persona que demanda y recibe ayuda personal muestra ciertos rasgos característicos si se atiende únicamente al número. Se trata de mujeres en su primera vejez, viudas y que viven solas o en un hogar extenso y que padecen algún tipo de discapacidad con un grado de severidad grave o total que les impide (o les dificulta gravemente) realizar ciertas actividades de la vida diaria. En efecto, el sexo es una de las variables más relevante en este caso. Las mujeres prácticamente duplican al número de hombres: 1.089 .770 mujeres frente a 580.680 varones. 
Gráfico 9. Población con discapacidad que recibe ayuda personal, por edad y sexo (números absolutos y relativos)

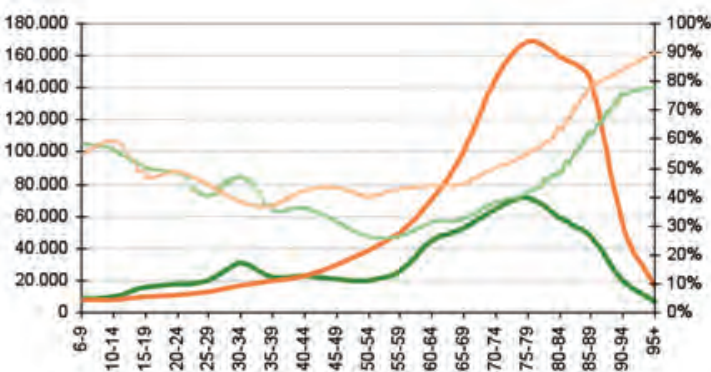

Fuente: elaboración propia a partir de la EDDES de 1999.

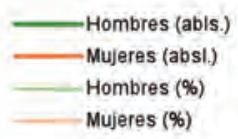

Mujeres (\%)

No obstante, existe en todo ello un importante efecto de la mayor supervivencia femenina y de la creciente desigualdad de efectivos de cada sexo a medida que se avanza en la edad. La percepción de cómo se relacionan con la intensidad de las ayudas personales se ve matizada cuando, en vez de números absolutos, se manejan las cifras relativas. Así, aunque el número de quienes reciben ayudas personales disminuya a partir de los 75-79 años, la proporción no hace más que aumentar, de forma constante, hasta alcanzar máximos en las edades avanzadas. Puede decirse por tanto que, a más edad, más ayudas se reciben. En cambio, se confirma que las mujeres, independientemente de su superioridad numérica en términos absolutos, reciben más ayudas que los hombres también en términos relativos. Entre las mujeres afectadas de 95 o más años, la recepción de cuidados personales alcanza a prácticamente el $90 \%$, frente al $78 \%$ de hombres de la misma edad. Esta proporción más elevada de mujeres puede estar relacionada con la mayor probabilidad que éstas tienen de acumular discapacidades y también de que éstas sean de mayor severidad, pero también con algunos condicionantes de género, como su mayor autoexigencia de «actividad» cotidiana, pero también con su mayor cercanía y el mantenimiento previo de las redes de apoyo familiar.

$\mathrm{Al}$ margen de las diferencias en función del sexo, la relación con la edad dibuja con claridad dos etapas vitales, la infancia y la vejez avanzada, en las que la intensidad con que se reciben cuidados personales es más elevada. Quienes ya han superado la primera infancia y padecen discapacidades sin recibir por ello ayudas personales van aumentando su proporción conforme van incrementándose también sus años de vida, y ello de forma sostenida hasta alcanzarse un mínimo en las edades maduras, de unos 50-54 años.

Sería precipitado atribuir esta menor proporción de ayudas a la simple desatención pública o familiar, ya que también guarda relación con una diferente casuística y tipología de las discapacidades y con distintas fases del ciclo vital, propias y del resto de la familia. Existen, por ejemplo, discapacidades que, con el tiempo, pueden paliarse, o quienes las padecen pueden alcanzar con la edad 
una competencia creciente en las tareas más afectadas. Por último, cabe añadir que las discapacidades más graves, aquéllas en que los cuidados resultan más necesarios, suelen ser también las causantes de una mayor sobremortalidad por parte de quienes las padecen. Pero, sobre todo, entre los menores con discapacidades, las ayudas personales se unen a los lógicos cuidados familiares dedicados a la infancia en general, en una relación difícil de discernir y que sólo se deshace a medida que se avanza en la edad de los afectados.

En cualquier caso, partir de los 55 años, la frecuencia de los cuidados recupera una relación directa con la edad que ya no abandonará. A los 75-79 años, la mitad de los afectados reciben ayudas, y a partir de los 95 años, la proporción es ya el $80 \%$ y el $90 \%$ de hombres y mujeres, respectivamente.

Este perfil se ve reflejado también en la distribución de las personas que reciben cuidados en función del tipo de actividades que se ven limitadas por la discapacidad. La mayor frecuencia de las ayudas se concentra en dos grandes grupos de actividades: las que afectan a las tareas del hogar y los desplazamientos, especialmente si se realizan fuera de la vivienda. En cambio, en términos relativos, sólo el $77 \%$ de tales personas recibe ayudas personales, mientras que entre las 235.201 personas que presentan dificultades para reconocer personas y objetos y para orientarse reciben este tipo de ayudas en el $95 \%$ de los casos. En general, son, en buena lógica, las personas que tienen afectadas las capacidades cognitivas y de mantenimiento de las funciones vitales básicas las que reciben ayuda con más intensidad, aunque no sean éstas las discapacidades más frecuentes.

\section{Los cuidadores}

En definitiva, más de la mitad de las personas que declararon padecer alguna discapacidad no necesitaron ningún tipo de cuidado personal por parte de terceros. Puede afirmarse, por lo tanto, que discapacidad no es sinónimo de dependencia, especialmente entre las personas de edad adulta madura.

Sin embargo, permanece la otra mitad, especialmente representada entre los mayores y, en general, por quienes sufren dificultades o impedimentos para el aprendizaje, la aplicación de conocimientos, el desarrollo de tareas, el cuidado de uno mismo o relacionarse con otras personas.

Esta necesidad de ayuda generada por ciertos tipos y grados de discapacidad se ha resuelto tradicionalmente en el propio hogar y por parte de familiares de forma mayoritaria, pero algunos factores históricos habían llevado a creer que se trataba de funciones que irían siendo progresivamente asumidas por otras instituciones, públicas o privadas. Esta creencia se había visto fomentada especialmente por la extensión de los sistemas de salud y de servicios sociales, junto al creciente prestigio de ciertas teorías sociológicas sobre el reparto de funciones de bienestar entre la familia, por una parte, y el Estado y el mercado, por otra. En la actualidad, sin embargo, esta claridad sobre la dirección hacia la que conduce el proceso de modernización social en estos temas se ha visto muy cuestionada. La EDDES, como muchas otras fuentes contemporá- 
Gráfico 10. Relación de parentesco del cuidador principal con el sujeto

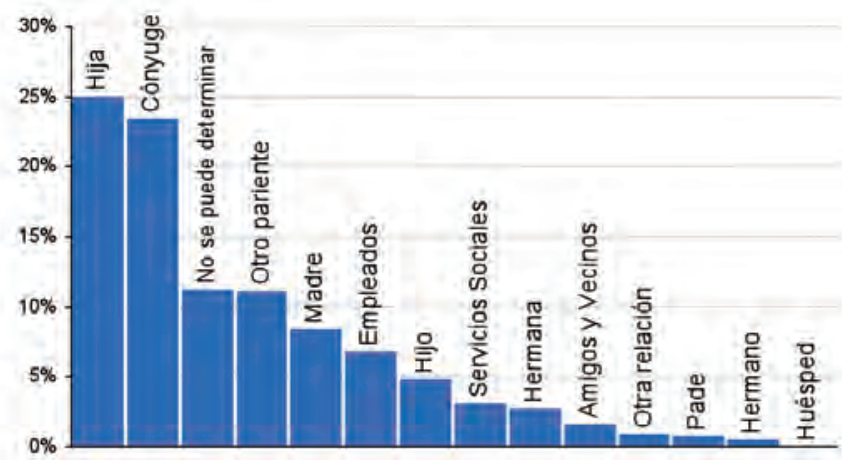

Fuente: elaboración propia a partir de la EDDES de 1999.

neas, pone en evidencia que la inmensa mayoría de los cuidados provistos a personas discapacitadas siguen suministrándose en el entorno familiar.

Según la EDDES, existen 1.670 .450 personas que reciben alguna ayuda por motivo de su discapacidad y, por lo tanto, debe existir, como mínimo, un número similar de personas que se dedican a proporcionar tales cuidados. En realidad, los necesitados de ayuda pueden recibirla de varias personas, aunque existe una a la que la EDDES considera como el «cuidador principal» 7 . Por eso, los más de millón y medio de cuidadores principales coexisten con otras 405.726 personas que, pese a no constar como tales, también proporcionan cuidados.

Aunque era lo que cabía esperar, no deja de resultar notable hasta qué punto la EDDES confirma la bien conocida primacía de los cuidados personales provinentes de la familia (el llamado sistema «informal») frente a los suministrados por otras instancias públicas o privadas, constituidas con dicho fin específico (el llamado sistema "formal»). No es sólo que los cuidadores principales pertenezcan en la mayoría de los casos al entorno familiar del sujeto, sino que generalmente son familiares muy próximos, como el cónyuge o la hija, que viven en el mismo hogar. Puede decirse abiertamente que el resto de la ayuda, tanto por parte de empleados como la que suministra nuestro estado de bienestar, representa sólo una pequeña parte de la asistencia personal que reciben los afectados por discapacidades en este país (gráfico 10).

Aunque exista un número elevado de casos en los que no se puede determinar la relación con el cuidador principal (el 11\%), en el 77\% quien se ocupa de dicha tarea es un familiar de la persona discapacitada y en el 66\% de los

7. La información que la EDDES proporciona de forma detallada se refiere a dicho cuidador principal, y sólo se constata la existencia de otros cuidadores. De la misma manera, se ve limitada a los cuidadores principales que conviven en el hogar, de manera que poco puede averiguarse sobre el resto, excepto el parentesco con el sujeto al que presta los cuidados. 
Gráfico 11. Distribución por edad, sexo y estado civil de los cuidadores principales
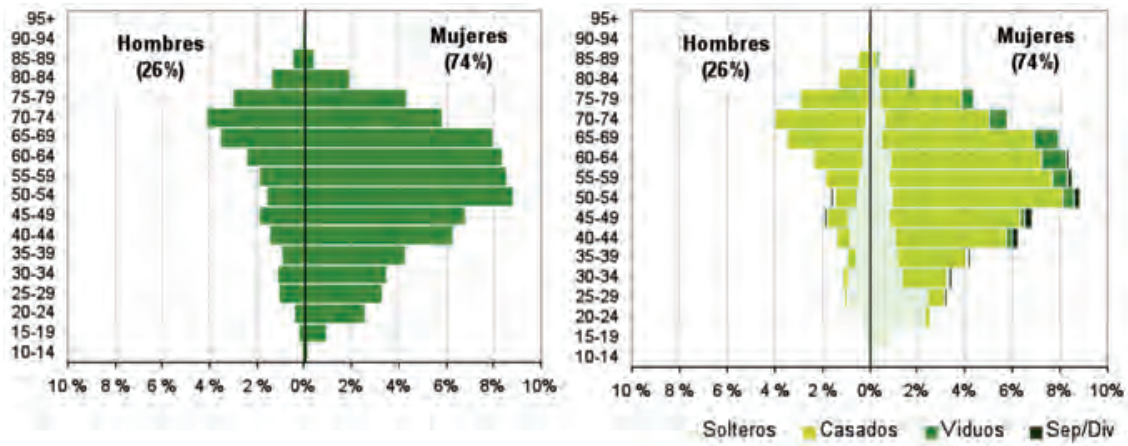

Fuente: elaboración propia a partir de la EDDES de 1999.

casos los vínculos de parentesco son estrechos (de filiación o fraternales). Las hijas y los cónyuges son quienes ejercen el rol de cuidadores principales con mayor frecuencia. No obstante, y como viene reiterándose hasta aquí en asuntos muy diversos, también en este punto la estrecha asociación entre la edad avanzada y la discapacidad es un factor explicativo de primer orden. Es esta asociación la que explica que los cuidadores ascendientes sean menos frecuentes, hasta el extremo de que los padres resultan incluso menos frecuentes que los empleados.

En cuanto a la relación residencial entre cuidador y cuidado, en un amplio porcentaje, el 70\% de los casos, se trata de personas que conviven en la misma vivienda. Tan solo un 10\% de los cuidados principales de dichas personas son asumidos por profesionales y generalmente se trata de empleados privados contratados por la persona interesada o su entorno.

No obstante, en la interpretación de estos datos, debe tenerse en cuenta la propia metodología de la EDDES (al elegir como objeto de atención prioritaria a uno sólo de los posibles cuidadores), que, en este caso, se combina con la adscripción más o menos tradicional de roles dentro de la unidad de convivencia. La falta de información sobre los cuidadores secundarios no excluye que los haya, de modo que el gráfico no puede interpretarse como falta de atenciones por parte del resto de la familia con la que se convive.

La EDDES ha contabilizado 777.321 mujeres cuidadoras principales, prácticamente el $74 \%$, frente a 271.420 hombres que realizan el mismo cometido. Aunque la abrumadora superioridad numérica de las mujeres como suministradoras principales de ayuda personal sea un hecho bien conocido y documentado, puede no resultar tan conocida la elevada edad de los cuidadores en general, de 55,1 años (53,5 si son mujeres y 59,5 años en el caso de los hombres). El reflejo de todo ello es claro en la pirámide por edad de los cuidadores principales (gráfico 11). 
Los cuidadores son, por tanto, personas como mínimo «maduras», y las proporciones más altas se dan entre los 50 y los 60 años. Se trata de las edades en que los propios progenitores se encuentran en una fase ya realmente avanzada de la vida, y los cónyuges empiezan a padecer discapacidades con una probabilidad significativa. En la diferente situación de ambos sexos, influye la pauta nupcial, históricamente muy sostenida, por la cual las mujeres se emparejan con hombres que, en promedio, tienen varios años más que ellas. En parte por el mismo motivo, los hombres cuidadores principales, además de menos numerosos, son también personas de más edad, y cabe suponer que es a sus mujeres a quienes cuidan en su mayor parte.

En cualquier caso, la asunción del rol cuidador es escasa entre los más jóvenes. Sólo el 8,8\% de ellos tiene menos de 30 años y, en cambio, los mayores de 50 años constituyen el 65,2\%. De hecho, más de un tercio son mayores de 65 años, lo que contradice la imagen corriente de la vejez como sinónimo exclusivo de dependencia. Los mayores padecen la discapacidad con mayor frecuencia, pero también protagonizan el cuidado de personas con discapacidad mucho más que las personas de otras edades.

Los principales cuidadores son mayoritariamente casados (el 71\%), sin que el peso de dicho estado civil muestre apenas diferencias si el cálculo se hace independientemente para los cuidadores de cada sexo. En cambio, sí resulta muy diferente la dedicación de los viudos respecto a las viudas $(1,3 \%$ y $7,3 \%$ respectivamente). De nuevo, todo apunta a que los hombres, que suelen fallecer con antelación (tanto por su sobremortalidad como por ser mayores que su pareja), ejercen como cuidadores principales mayoritariamente en el cuidado a sus esposas, mientras que una parte muy considerable de las mujeres que han perdido a su pareja ejerce, aún así, como cuidadora de alguna otra persona. Pese a todo, y aunque en las edades avanzadas la viudedad constituye un estado civil de gran peso (mayoritario incluso entre las mujeres de más edad), se cumple en ambos sexos que los viudos tienen un peso menor entre el conjunto de cuidadores, muy inferior al de los casados en general e incluso al de los solteros (que constituyen el $21 \%$ de los cuidadores principales).

Con todo lo apuntado hasta aquí, se acumulaban indicios de que la tipología de los afectados por discapacidades que reciben ayuda personal guarda una estrecha relación con las características (edad, sexo, estado civil, etc.) de sus cuidadores principales. La Tabla 1 refleja finalmente quién cuida de quién. En los títulos de las columnas, se han ubicado los cuidadores principales por alguna de sus características y la proporción que constituyen sobre el total de cuidadores principales. En las filas, las personas a las que prestan dichos cuidados.

Existen claras diferencias entre las personas que se benefician de los cuidados en función de si el cuidador principal es un hombre o una mujer. Se confirma ahora que ellas cuidan en general a un abanico más amplio de gente, independientemente de su edad y que, en efecto, ellos ejercen dichas funciones en los casos en que es la esposa quien requiere cuidados. La principal excepción a esta pauta es la de los hombres solteros, que, aunque escasos, se centran casi exclusivamente en el cuidado de sus progenitores, en sus madres sobre todo. 
Tabla 1. Relación de parentesco entre cuidador principal y receptor de cuidados

\begin{tabular}{|c|c|c|c|c|c|}
\hline $\begin{array}{l}\text { Cuidador principal/ } \\
\text { Persona de la que cuidan }\end{array}$ & $\begin{array}{c}\text { Mujeres } \\
\text { mayores } \\
\text { de } 50 \text { años } \\
(28 \%)\end{array}$ & $\begin{array}{c}\text { Mujeres } \\
\text { mayores } \\
\text { de } 50 \text { años } \\
(44 \%)\end{array}$ & $\begin{array}{c}\text { Hombres } \\
\text { solteros de } \\
\text { menos de } \\
30 \text { años } \\
(2 \%)\end{array}$ & $\begin{array}{c}\text { Hombres } \\
\text { casados de } \\
\text { más de } \\
30 \text { años } \\
(18 \%)\end{array}$ & $\begin{array}{c}\text { Hombres } \\
\text { casados de } \\
\text { más de } \\
50 \text { años } \\
(16 \%)\end{array}$ \\
\hline Cónyuge & $11,3 \%$ & $39,1 \%$ & $0 \%$ & $87,3 \%$ & $90,5 \%$ \\
\hline Madre & $43,1 \%$ & $19,8 \%$ & $71,1 \%$ & $2,5 \%$ & $1,7 \%$ \\
\hline Padre & $7,7 \%$ & $3,7 \%$ & $14,2 \%$ & $1,4 \%$ & $0,5 \%$ \\
\hline Hermano/a & $3,0 \%$ & $7,6 \%$ & $9,4 \%$ & $0,8 \%$ & $0,6 \%$ \\
\hline Hijo & $8,9 \%$ & $11,3 \%$ & $0,0 \%$ & $3,3 \%$ & $3,1 \%$ \\
\hline Hija & $6,5 \%$ & $7,4 \%$ & $0,0 \%$ & $1,2 \%$ & $1,1 \%$ \\
\hline Otro pariente & $14,9 \%$ & $9,3 \%$ & $4,4 \%$ & $3,0 \%$ & $2,1 \%$ \\
\hline
\end{tabular}

Fuente: elaboración propia a partir de la EDDES 99.

También las mujeres cuidadoras menores de 50 años dedican mayoritariamente su ayuda a sus madres. A partir de esta edad, las mujeres pasan a prestar cuidados más frecuentemente a sus cónyuges que a cualquier otro familiar. A pesar de ello, las mujeres cuidadoras mayores de 50 años constituyen nada más y nada menos que el $44 \%$ de todos los cuidadores principales, y los beneficiarios, además de ser muy numerosos, son muy diversos. Los hombres de tales edades, un 19\% del total de cuidadores, confirman, en cambio, su peculiaridad dedicándose casi exclusivamente a su cónyuge, pauta que no hace más que acentuarse cuanto más elevada es su edad.

Por último, si se hace la distinción del tipo de actividad laboral desempeñada por el cuidador, cabe destacar otro de los rasgos que caracterizan a este colectivo: el peso abrumador de las mujeres va acompañado, en todas las edades, de un componente ampliamente mayoritario de las que se dedican principalmente a las labores del hogar ${ }^{8}$. Solamente ellas representan el 36\% del total de todos los cuidadores principales.

No obstante, también destaca por su elevada presencia y, sobre todo, por sus características, la población mayor jubilada, hombres en su mayoría. Constituyen algo más del $21 \%$ del total de los cuidadores. Es un hecho que debería llevar a considerar la imagen de dependencia que frecuentemente se tiene de este colectivo, tanto por mayor como por masculino, y a investigar en el futuro qué cambios se están produciendo en los roles de género, no sólo entre los jóvenes, sino también entre los mayores.

La fuente permite analizar muchos otros componentes relacionados con las pautas de cuidado, sobre los que sólo es posible hacer algún apunte para no rebasar la extensión prudente en un artículo.

8. En esta categoría, no se incluyen aquellas personas que se dedican activamente y dentro del mercado laboral a las tareas domésticas. 
Gráfico 12. Relación con la actividad de los cuidadores principales

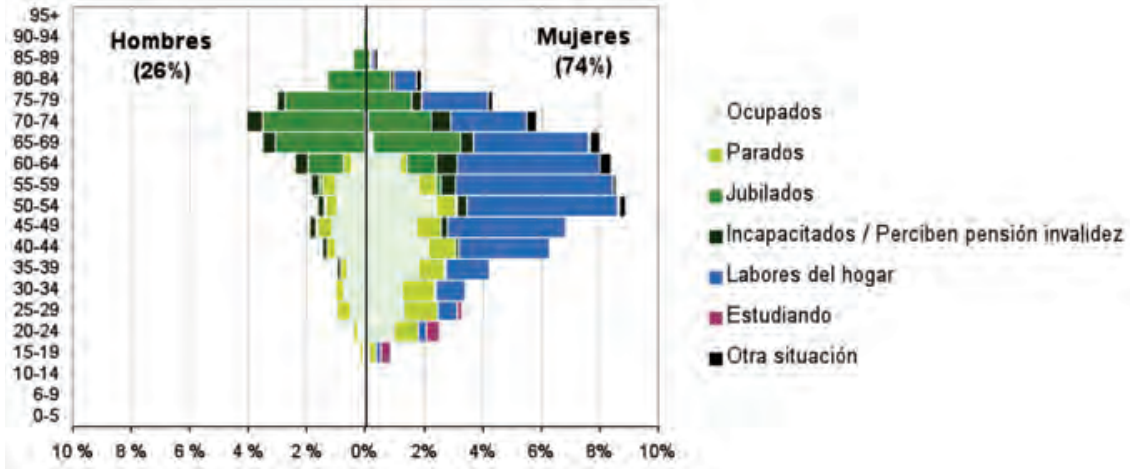

Fuente: elaboración propia a partir de la EDDES de 1999.

En cuanto a las compensaciones a los cuidados, a tenor de los datos obtenidos acerca de los responsables de dichas funciones, no es de extrañar que solamente el $11 \%$ de los cuidadores reciba algún tipo de contraprestación económica, y que, en la gran mayoría de los casos, el $71 \%$, los receptores de dichas compensaciones sean precisamente quienes ejercen profesionalmente dicha función (por contrato privado o por adjudicación desde instituciones públicas).

En lo que se refiere a su duración, la mayor parte de los cuidados vienen desarrollándose durante un tiempo considerable. Las personas que los proporcionan desde hace menos de cuatro años no llegan a ser la mitad (46\%), mientras que más de una tercera parte de los cuidadores lleva más de ocho años en dicho empeño. Los familiares más directos son los que más tiempo

Gráfico 13. Cuidadores principales, según la relación con quien recibe cuidados, la duración en años de los cuidados y el número de horas semanales dedicadas
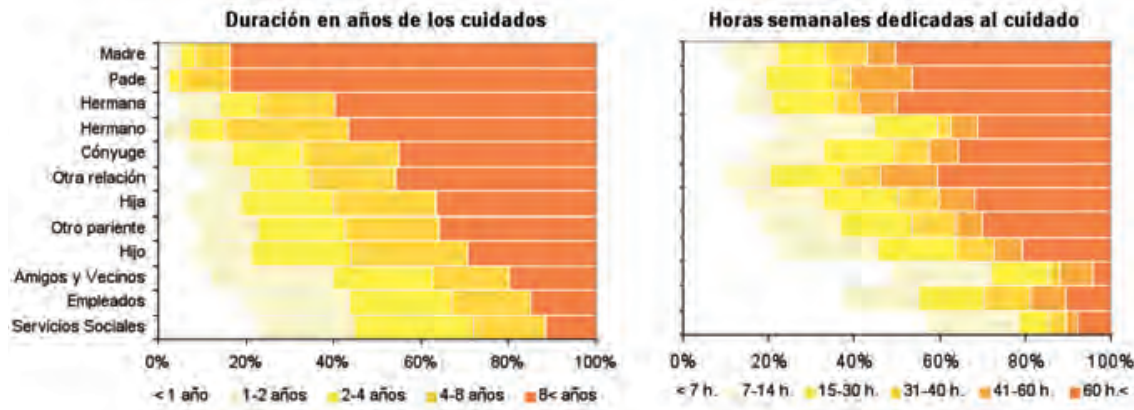

Fuente: elaboración propia a partir de la EDDES de 1999. 
llevan cuidando de alguien, sobre todo las madres y los padres (aunque sean muy pocos), seguidos de hermanos y hermanas. La antigüedad de la relación de parentesco que mantienen es la que les une con la persona a la que cuidan.

Además del tiempo que llevan cuidando, si se tienen en cuenta las horas semanales que se dedican a dicha función, los familiares directos son también los que más intensamente prestan cuidados, aunque en este caso los hombres pierden posiciones, ya que su dedicación disminuye en relación con las mujeres cuidadoras.

Viendo las características que presenta la ayuda personal prestada por los cuidadores principales, no es de extrañar la elevada corresidencia entre la mayoría de los cuidados y cuidadores. Si se tiene en cuenta también que esta relación no disminuye con la severidad de las discapacidades, resulta conveniente plantear un examen más profundo sobre la relación entre los cuidados formales e informales en nuestro país.

\section{Últimos apuntes y consideraciones}

Como puede comprobarse, estamos ante una fuente de información de una riqueza y complejidad sin precedentes. Sus resultados son abrumadores respecto al protagonismo de la edad como variable determinante en todo aquello que tiene que ver con la salud, pero también con el grado de adaptación al entorno físico y a las relaciones de ayuda e intercambio con el entorno humano. Puesto que la salud y la vejez son dos dimensiones esenciales de los espectaculares cambios poblacionales que está experimentando España en las últimas décadas, la explotación de una fuente como ésta, tan detallada y estadísticamente consistente pero sin continuidad temporal, no hace más que provocar y dibujar con mayor claridad los interrogantes sobre las direcciones en que se mueve dicho proceso de cambio.

En particular, se hace necesaria una observación continuada que contraste algunos supuestos ampliamente extendidos que podrían no verse avalados empíricamente. Ha podido comprobarse que, en efecto, existe relación directa entre edad y necesidad de cuidados, pero estamos lejos de poder separar los efectos de la edad y los de la generación, éstos últimos de gran importancia en un país como España, en el que la historia parece haber corrido tan rápidamente que todavía están vivas personas nacidas en un mundo preindustrial. Aunque parezca sorprendente, también se están constatando mejoras sustanciales en la salud de los mayores, y éstas se producen con una rapidez inusitada que relativiza el vínculo automático entre salud y edad.

Pero, sobre todo, estamos lejos de determinar qué efecto conjunto tiene el envejecimiento demográfico, tan relevante en todas las variables analizadas, en la disponibilidad y continuidad de los cuidados informales. Con demasiada frecuencia se da por supuesta una progresiva degradación en la relación numérica existente entre quienes requieren tales cuidados y quienes los proporcionan, bajo la suposición adicional de que unos son los mayores y los otros son los adultos, especialmente las mujeres, que cada vez estarán menos disponibles a 
medida que las tasas de actividad femenina se igualen a las de los hombres. Pero dicho supuesto debería tener en cuenta algo que en la EDDES se constata con gran claridad: el perfil de los cuidadores se desplaza de las mujeres adultas hacia las personas maduras mayores de ambos sexos, de manera que el propio envejecimiento demográfico podría estar incrementando, no deprimiendo, el peso de los cuidadores en el conjunto de la población (Pérez Díaz, 2003b).

En definitiva, la rapidez e intensidad de los cambios sociodemográficos hace necesario, una vez más, replantear tópicos y modificar posiciones analíticas que se ven desbordadas. La intensa imbricación de los cambios en la supervivencia, la reproducción, los roles de género, las pautas familiares y las características y el peso de cada edad compone un ámbito de estudio apasionante en el que todavía queda mucho por hacer.

\section{Bibliografía}

Abellán GarCía, A. (2003). «El riesgo de discapacidad entre los mayores». Revista Multidisciplinar de Gerontologia, 13 (3), 214-217.

Actis, W.; Prada, M.A. de y Pereda, C. (2004). Les desigualtats socials entre la població catalana amb discapacitats. Barcelona: Fundació Jaume Bofill. 211 páginas.

Campo LaRedo, M.J. (2000). Apoyo informal a las personas mayores y el papel de la mujer cuidadora. Madrid: Centro de Investigaciones Sociológicas.

CaSAdo Marín, D. y López I CASASNOVAS, G. (2001). Vejez, dependencia y cuidados de larga duración en España. Barcelona: Fundació "la Caixa".

COLECTIVO IOE (2003). La inserción laboral de las personas con discapacidades. Barcelona: Fundació "la Caixa", 190 p.

CONSEjo ECONÓMICO y SOCIAL (2004). La situación de las personas con discapacidad en España. Madrid, 223 páginas.

Durán Heras, M.Á. (2002). Los costes invisibles de la enfermedad. Bilbao: Fundación BBVA.

FogEL, R.W. y COSTA, D.L. (1997). «A theory of technophysio evolution, with some implications for forecasting population, health care costs, and pensions costs». Demography, 34 (1), 49-68.

FUNDACIÓN INTRAS (2003). Población con enfermedad mental grave y prolongada. Madrid: IMSERSO, $353 \mathrm{p}$.

García Calvente, M.M.; Mateo Rodríguez, I. y Gutiérrez Cuadra, P. (1999). Cuidados y cuidadores en el sistema informal de salud. Granada: Escuela Andaluza de Salud Pública.

INE (1987). Encuesta sobre discapacidades, deficiencias y minusvalias 1986. Resultados nacionales. Madrid, 2 tomos.

- (2001). Encuesta sobre discapacidades, deficiencias y estado de salud, 1999. Metodología. Madrid.

- (2005). Encuesta sobre discapacidades, deficiencias y estado de Salud 1999. Informe general. Madrid: INE, IMSERSO y Fundación ONCE.

Jiménez Lara, A.; Huete García, A. y García Díaz, N. (coords.) (2002). La discapacidad en cifras. Madrid: IMSERSO, $208 \mathrm{p}$.

Jiménez Lara, A. y Huete GarCíA, A. (2003). Las discapacidades en España: datos estadísticos. Aproximación desde la Encuesta sobre discapacidades, deficiencias y estado de salud, 1999. Madrid: Real Patronato sobre Discapacidad, 196 p. 
Ministerio de Trabajo y Asuntos Sociales (1997). Clasificación internacional de deficiencias, discapacidades y minusvalias. 3a ed. Madrid: IMSERSO, 290 p.

Puga GonZÁlez, M.D. (2002). Dependencia y necesidades asistenciales de los mayores en España, una previsión a 2010. Madrid: Fundación Pfizer

Puga GonzÁlez, M.D. y Abellán GarcíA, A. (2004). El proceso de discapacidad. Un análisis de la Encuesta sobre discapacidades, deficiencias y estado de salud. Alcobendas (Madrid): Fundación Pfizer, 216 p.

PÉrEz DíAz, J. (2003a). La madurez de masas. Madrid: Imserso.

- (2003b). «Feminización de la vejez y estado del bienestar en España». Revista Española de Investigaciones Sociológicas, 104, 91-121.

Rodríguez Cabrero, G. (2004). Protección social de la dependencia en España. Madrid: Fundación Alternativas, p. 67.

Yanguas Lezaun, J.J.; Leturia Arrazola, F.J. y Leturia Arrazola, M. (2001). Apoyo Informal y cuidado de las personas mayores dependientes. [http://www.matiaf.net/pro fesionales/articulos]. 